\title{
Symptom Brustschmerz für ACS nicht sensitiv
}

\author{
Die „typischen“ Symptome der Angina pectoris haben Generationen von Ärzten gelernt. \\ Eine US-Studie legt nun nahe, dass ihre Sensitivität und ihr prädiktiver Wert eher dürftig sind.
}

_ Jeder zehnte Patient, der in die Notaufnahme kommt, hat Brustschmerzen. Natürlich denkt man bei diesem Symptom in erster Linie an ein akutes Koronarsyndrom (ACS). Tatsächlich wird nach Abschluss der Behandlung nur bei 15-20\% dieser Patienten diese Diagnose gestellt. Andererseits wissen wir, dass mehr als die Hälfte der ACS-Patienten kein typisches EKG hat und mindestens 10\% auch kein erhöhtes Troponin aufweisen. Die klinische Symptomatik spielt also eine wichtige Rolle bei der Diagnose, was naturgemäß zu Unsicherheit, längerer Beobachtung und nicht erforderlicher stationärer Aufnahme führen kann.

Wie zuverlässig das Symptom Brustschmerz für ein tatsächlich vorhandenes ACS ist, wurde nun in einer prospektiven, monozentrischen Untersuchung in der Nothilfe eines englischen Krankenhauses untersucht. Eingeschlossen wurden 912 Patienten ohne diagnoseweisendes EKG, bei denen der Aufnahmearzt nach mehr als sechs Stunden noch eine TroponinBestimmung für erforderlich hielt.

Die Ärzte sollten nun nach eigenem klinischem Urteilsvermögen und ohne Kenntnis des Troponin-Befundes einschätzen, ob diese Patienten eine typische Angina pectoris oder untypischen Brustschmerz aufwiesen. Bei 114 Patienten $(12,5 \%)$ sprach das hochsensitive Troponin-Assay für ein ACS.

157 (17,2\%) Patienten unterzogen sich einer Koronarangiografie. Von diesen hatten nur 57,3\% auch eine Troponin-Erhöhung. $66,7 \%$ hatten eine signifikante koronare Herzkrankheit. Immerhin 42,7\% Patienten wurden trotz normalem Troponinwert angiografiert, wobei in dieser Gruppe dennoch 46,2\% einen wesentlichen Koronarbefund aufwiesen.

Für die Diagnose eines ACS hatte der sogenannte typische Brustschmerz hinsichtlich seiner diskriminatorischen Fähigkeiten nur eine Fläche unter der Kurve von 0,54 . Zum Trost für die ärztliche
Kunst bestand wenigstens ein Unterschied zwischen erfahrenen Ärzten und Berufsanfängern. Die Spezifität der Diagnose „akutes Koronarsyndrom“ lag bei den erfahrenen Ärzten bei $65,8 \%$, bei den Anfängern waren es 55,4\%.

- Carlton EW et al. Chest pain typicality in suspected acute coronary syndromes and the impact of clinical experience. Am J Med. 2015;128:1109-16

\section{KOMMENTAR}

Auch wenn es schwer fällt, sich das einzugestehen: Bei Lichte betrachtet ist die Sensitivität des Symptoms "typischer Brustschmerz" zu gering, um in der Diagnostik die ihm heute noch zugeordnete Rolle zu spielen. Leider können auch hochsensitive Troponin-Assays diese Lücke nicht vollständig füllen. In der Studie hatten mehr als 40\% der Patienten einen relevanten Koronarbefund, obwohl das Troponin nicht erhöht war. Zwei Drittel dieser Patienten benötigten eine Intervention. Auch die klinische Erfahrung verbessert die diskriminatorische Fähigkeit des Symptoms "typischer Brustschmerz" nur wenig. Wir werden wohl mit dieser Unsicherheit leben müssen.

Prof. Dr. med. H. S. FüeßI

\section{Hier steht eine Anzeige.}

